\title{
Oral Mucosal Lesions as Initial Presentation in Lupus Erythematosus Patient (A Case Report)
}

\author{
Rani Handayani \\ Oral Medicine Residency Program \\ Faculty of Dentistry, Universitas Indonesia \\ Jakarta, Indonesia \\ rani.handayani05@gmail.com
}

\author{
Gus Permana Subita \\ Department of Oral Medicine \\ Faculty of Dentistry, Universitas Indonesia \\ Jakarta, Indonesia \\ guspermana11@gmail.com
}

\author{
Siti Aliyah Pradono \\ Department of Oral Medicine \\ Faculty of Dentistry, Universitas Indonesia \\ Jakarta, Indonesia \\ aliyah.pradono@gmail.com
}

\begin{abstract}
Lupus erythematosus (LE) is a chronic inflammatory disease caused by interference of the immune system. There are several criteria to establish a diagnosis of this disease including oral mucosal lesions. Oral mucosa lesions are an important part because they can be the initial presentation of LE. The objective of this case report was to describe oral mucosal lesions as initial presentation of $\mathrm{LE}$ disease without involvement of other organs. A 47-year-old female came to the Oral Medicine Clinic at RSUPN Cipto Mangunkusumo Jakarta with complaints of a five-month history of soreness on her inner cheek, tongue and severe crusted lips without fever. Patient had been taken drug containing paracetamol and caffeine every day since 2 years ago without any doctor's prescription. Clinical finding seen were erosion and blackish brown crusted on the lips; macular and irregular ulcer, surrounded by reddish color with diffuse borders on the buccal mucosa; sloughing and keratotic papules on the tongue. The working diagnosis on the first visit is Oral Lichen Planus. At the next visit, after clinical evaluation and referral to the Immunological Allergy Department were done, the patient was diagnosed of LE. Topical dexamethasone was prescribed and the patient are required for follow up each one week. The patient given advice to follow Immunological Allergy Department's treatment plan. Oral mucosal lesions may be the initial appearance of $\mathrm{LE}$ patient. Early diagnosis is important for LE comprehensive treatment, so that the morbidity can be reduced and survival rate can be increased.
\end{abstract}

Keywords-oral lesions, lupus erythematosus, initial presentation

\section{INTRODUCTION}

Lupus erythematosus (LE) is a chronic inflammatory disease caused by the disruption of relapsed immune disorders [1]. It was first introduced by Biett in 1828 and Kaposi in 1872 [2]. LE consists of Discoid Lupus Erythematosus (DLE) and Systemic Lupus Erythematosus (SLE) and can occur in all age groups by mean from 21-50 years old [3,4].

A study showed that there was a tendency of increasing LE incidence with improvement of survival rates in LE patients. Another study in 1990 revealed that $70 \%$ of LE patients could survive in last 20 years [9]. More than 1.5 million people in United States have been diagnosed with LE but in Asia, the prevalence is higher in Shanghai and lower in India and Japan [5,9].

There are eight criterias in establishing diagnosis of LE [5]. The presence of oral lesion is one feature that commonly appears in early phase and included as diagnostic criteria of LE. However, the prevalence of oral involvement may be uncertain [6,8]. Oral mucosal lesion in LE patients has a wide spectrum of appearance, it results dentist may be confused to differ this lesion to other similar oral diseases, such as Oral Lichen Planus (OLP), Erythema Multiforme (EM). Consequently, it may lead to delayed diagnosis and management [7,22]. Early treatment could help LE patient increase their survival rates.

Here we report a case of early detection of LE by clinical finding of oral mucosa lesions and immunologic test.

\section{CASE REPORT}

A 47-year-old female came to the Oral Medicine Clinic at RSUPN Cipto Mangunkusumo Jakarta with complaints of a five-month history of soreness on her inner cheek, tongue and severe crusted lips without fever. The patient had visited an internist at one of the hospitals in Jakarta with the same complaints includein his palate and had been given mouthwash. Patients had also performed complete blood examinations, kidney and liver function tests, and Human Immunodeficiency Virus (HIV) screeningtest. All of examination results are within a normal range but the complaint persists. Patients had a history of taking drugs containing paracetamol and caffeine every day since 2 years ago without a doctor's prescription.

Extra oral examination showed theerosive lips with a blackish brown crusted withoutother lesions on the facial skin area (Figure 1). Intra oral examination showed a shallow erosive lesion of the labial mucosa 
adjacent to the vermilion border (Figure 2); the lesions on the buccal mucosa were bilateral whitish macula surrounded by erythema with diffuse borders (Figure 3 and 4); sloughing and keratotic papules on the lateral tongue (Figures 5). In addition, she had bad oral hygiene, sub and supra gingival calculus was accompanied by inflammation of the gingival margin, and radix 18,17,16,14,12,22,23,36,35,34.

Based on the clinical appearance and adjuvant examination results obtained from the previous hospital, the patient was diagnosed with Oral Lichen Planus with a differential diagnosis of Lupus Erythematosus.

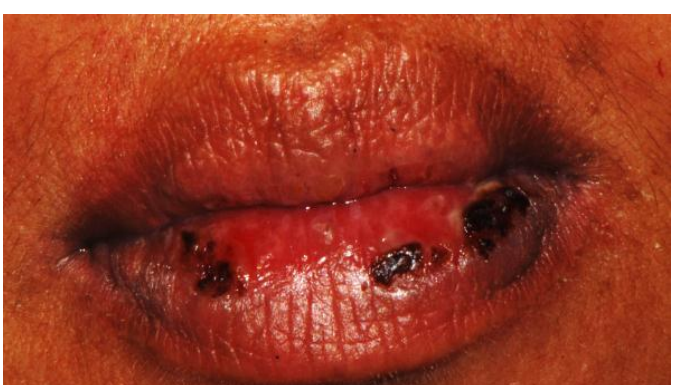

Figure 1. The erosive lips with a blackish brown crusted.

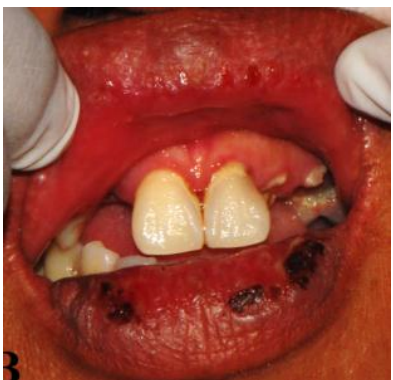

Figure 2. Shallow erosive lesion of the labial mucosa adjacent to the vermilion border.

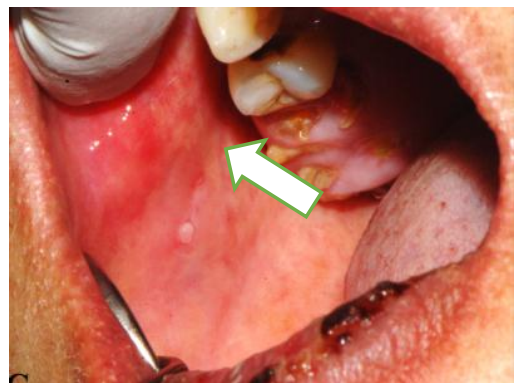

Figure 3. The lesions on the right buccal mucosa showed whitish macula surrounded by erythema color with diffuse borders.

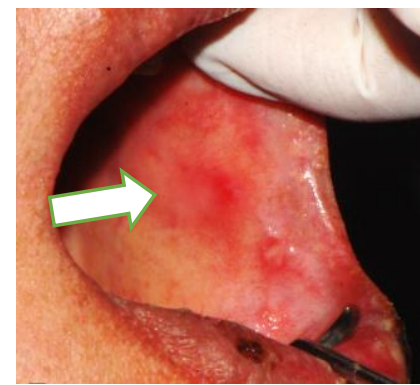

Figure 4. The lesions on the left buccal mucosa showed whitish macula surrounded by erythema color with diffuse borders.

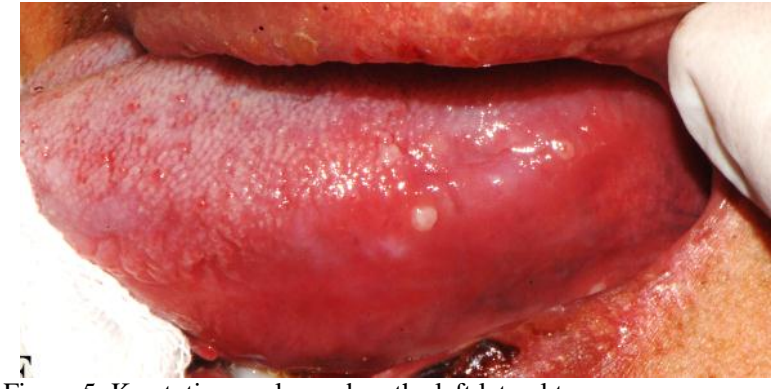

Figure 5. Keratotic papules and on the left lateral tongue.

\section{CASE MANAGEMENT}

On the first visit, the patient was given a corticosteroid-containing ointment applied to the lesion on the lips, dexamethasone mouthwash at the morning and afternoon, a multivitamin containing antioxidants and was suggested to do follow up visit every weeks. Patients are also planned to eliminate focus infection and maintain good oral hygiene.

On the second visit, there were improvements in lesions in the buccal and tongue mucosa, but not for the lip area. Where the reddish area of the buccal mucosa and the keratotic area on the tongue begins to thin; but the lesions and crusts on the lips persist.Patients still complain of pain and bleeding on the lip area. Patients were given a taperingdose in mouth rinse dexamethasone but not for lip ointment.

On the third visit, in the buccal and buccal mucosa seen recurrent lesions such as the first visit and lesions on the lips was persist. The patient was referred to the Allergy and Immunology Department of RSUPN Cipto Mangunkusumo for evaluation and management of oral mucosal lesions that did not respond to our treatment. The results of the Allergy and Immunology Department examination showed a decrease in hematocrit values, high eosinophil and Ig E values, and positive ANA examination with a rough speckled pattern, 1/100 titer, anti UI-Nrnp, anti-S, possible diagnosis of systemic LE. Furthermore, patients follow the treatment plan of Allergy and Immunology Department of RSUPN Cipto Mangunkusumo.

\section{DISCUSSION}

Lupus erythematosus (LE) is an autoimmune disease that affects the oral mucosa in both cutaneous and systemic forms with a wide range of prevalence [16]. The prevalence of LE in the United States is about 500/ one million cases with an annual incidence of 70/ one million population, with more cases of cutaneous LE 2-3 times of systemic LE cases [10]. A study in the United States found that the highest prevalence of LE cases was in blacks. While in the Asian region is known the highest prevalence in the city of Shanghai, where textile factory workers who were predominantly female and exposed to environmental risk factors than India, Japan and Saudi Arabia [9]. Data released by the Foundation Lupus Indonesia is known in Indonesia LE patients increased from 12,700 in 2012 to 13,300 inhabitants per April 2013 [24]. LE suffered more by women than men especially during reproductive period 
[12]. Life expectancy increased over the last 5 years in Asia Pacific countries, 60\% Australia, 94\% South Korea, 97\% Hong Kong, 98\% China (Shanghai), whereas in the last 10 years $70 \%$ of Malaysia, and $94 \%$ of Hongkong [15]. High mortality rates in men versus women due to cardiovascular disorders resulting from the habit of smoking [12]. Death rates over the past decade appear to be decreasing due to good governance of LE cases and enforcement this case at the beginning of the period [14]. In Asia, infection and active systemic LE become the first factor in the cause of death in the early and late phases so that for the Asian region shows a worse prognosis than any other country [15]. Lupus nephritis is the leading cause of death for LE cases [14]. The Michigan Lupus Epidemiology and Surveillance Program reports at least 133 new cases each year [11]. This will be a challenge in the early diagnosis and proper management of patients with LE.

Clinical features of LE on heterogeneous oral mucosa make it difficult to establish diagnosis. There are frequently overlap of diagnosis with other cases such as Oral Lichen Planus, Erythema Multiforme and Pemphigus Vulgaris [14,16]. According to the American College of Rheumatology's LE criteria in 1982 which was then revised in 2012 by Systemic Lupus International Collaborating Clinics (SLICC) oral mucosal lesions more than $54 \%$ of patients with LE with ulcers were the most commonly revealed lesions in which $44 \%$ were for sensitivity and $92 \%$ for specificity $[6,18,19]$. Oral manifestations were symptomatic in cases of LE where $40 \%$ for SLE and $24 \%$ for cases of DLE [22]. The most common areas for oral mucosal lesions are the palate, the buccal mucosa (22.3\%); lips $(12.2 \%)$ especially the lower lip in the form of erythema, erosive, and crusta [6,16,23]. Clinical features of LE oral lesions vary widely with various terms used include oral discoid lesion, chronic plaque, lupus cheilitis, acute ulcer, ulcer oral, red ulcer, ulcerative plaques, pebbly red areas, honeycomb lesions, keratotic lesions, keratotic white plaques, purpura lesions and petechial diffuse palatal erythema [21].

In this case, the clinical appearance of this patient looks like an Oral Lichen Planus whereby in buccal mucosa, it appeared an area of erythema and in lateral of tongue, there was a sloughing area accompanied by papule keratotic. That is why the initial diagnosis we established is Oral Lichen Planus.

Most lesions on lips may cause a dilemma in diagnosis and management for dentist. Early identification basically can be performed with a thorough history of lesions, previous symptoms, and associated habits [20]. The appearance of erosive and crusting lip areas may quite be similar to Pemphigus Vulgaris (PV) or Erythema Multiforme (EM). Distinguishing LE, PV, and EM is clinically difficult. Biopsy is required in addition for histopathological examination [22]. But in this case, the biopsy is not done because of patient's refusal.
After one-month re-evaluation of clinical features and ANA test, the diagnosis of LE was made. According to LE criteria of Systemic Lupus International Collaborating Clinics (SLICC) in 2012, there is at least one clinical criterion and an immune criterion that can be used in diagnosing LE [19]. The Indonesia Lupus Foundation pocket book stated that grouping diagnosis of LE is done based on whether fast or not the disease is detected. It can be divided in four groups: early detection, mild lupus, severe lupus and life-threatening lupus [24]. It is suitable to our case in which one clinical criteria of lesions in buccal mucosa, tongue and lips and an immune criterion of positive ANA examination.

Oral hygiene and the prevalence of oral mucosa lesions in LE patients are significantly correlated. Good oral hygiene will decrease the prevalence of oral mucosal lesion. Unfortunately, the patient had poor oral hygiene. It was seen from the appearances of calculus and radix. This condition may slow healing process of erythematous and ulcerative lesions in this patient. Thus, it is important to give communication, information, and education about how to maintain oral hygiene and eliminate focus infection [6].

In this case report, we also describe that oral mucosal lesions can be as a preliminary feature of LE symptoms in patients. It is necessary to collaborate with multi-disciplinary professionals to achieve proper diagnosis and management of LE patient. As a result, comprehensive care can be provided to reduce morbidity and increase life expectancy of LE patients.

Finally, we recommend this paper can be upgraded to be an advanced study so the profile of oral mucosa lesions in patients with LE can be more revealed. Thus, it can be a good information for other health practitioners.

\section{REFERENCES}

[1] S. Akarsu, O. Ozbagcivan, F. Semiz, S. Aktan, "High prevalence of metabolic syndrome in patients with discoid lupus erythematosus: A cross-sectional, case-control study," J. Immunol. Res., vol. 2017, pp. 3972706, 2017.

[2] A.M. Ranginwala, M.M. Chalishazar, P. Panja, K.P. Buddhdev, H.M. Kale, "Oral discoid lupus erythematosus: A study of twenty-one cases," J. Oral Maxillofac. Pathol., vol. 16(3), pp. 368-373, September 2012.

[3] K. Kranti, H. Seshan, J. Juliet, "Discoid lupus erythematosus involving gingiva," J. Indian Soc. Periodontol., vol. 16(1), pp. 126-128, 2012.

[4] S. Panjwani, "Early diagnosis and treatment of discoid lupus erythematosus," J. Am. Board. Fam. Med., vol. 22(2), pp. 206213, March 2009.

[5] S.S. De Rossi, M. Glick, "Lupus erythematosus: considerations for dentistry,” J. Am. Dent. Assoc., vol. 129(3), pp. 330-339, 1998.

[6] M. Khatibi, A.H. Shakoorpour, Z.M. Jahromi, A. Ahmadzadeh, "The prevalence of oral mucosal lesions and related factors in 188 patients with systemic lupus erythematosus," Lupus, vol. 21(12), pp. 1312-1315, October 2012.

[7] W.M. Mandy Chan, S.M. Pang, S.K. Ng, "Severely crusted cheilitis as an initial presentation of systemic lupus erythematosus," Indian J. Dermatol., vol. 62, pp. 440, September 2017.

[8] S.V. Lourenço, M.N. Sotto, M.A.C. Vilela, F.R.G. deCarvalho, E.A. Rivitti, M.M.S. Nico, "Lupus erythematosus: clinical and histopathological study of oral manifestations and 
immunohistochemical profile of epithelial maturation," J. Cutan. Pathol., vol. 33(10), pp.657-662, 2006.

[9] E. Osio-Salido, H. Manapat-Reyes, "Epidemiology of systemic lupus erythematosus in Asia," Lupus, vol. 19(12), pp. 13651373, October 2010

[10] M.T. Brennan, M.A. Valerin, J.J. Napeñas, P.B. Lockhart, "Oral manifestations of patients with lupus erythematosus," Dent. Clin. North Am., vol. 49(1), pp. 127-141, January 2005.

[11] E.C. Somers, W. Marder, P. Cagnoli, E.E. Lewis, P. DeGuire, C. Gordon, C.G. Helmick, L. Wang, J.J. Wing, J.P. Dhar, J. Leisen, D. Shaltis, W.J. McCune, "Population-based incidence and prevalence of systemic lupus erythematosus: the Michigan lupus epidemiology and surveillance program," Arthritis Rheumatol., vol. 66(2), pp. 369-378, February 2014

[12] J. Hwang, J. Lee, J.K. Ahn, E.J. Park, H.S. Cha, E.M. Koh, "Clinical characteristics of male and female Korean patients with systemic lupus erythematosus: A comparative study," Korean J. Intern. Med., vol. 30(2), pp. 242-249, March 2015.

[13] V. Golder, R. Kandane-Rathnayake, A.Y.B. Hoi, et al., "Frequency and predictors of the lupus low disease activity state in a multi-national and multi-ethnic cohort," Arthritis Res. Ther., vol. 18, pp. 260, 2016.

[14] D.E. Furst, A.E. Clarke, A.W. Fernandes, T. Bancroft, W. Greth, S.R. Iorga, "Incidence and prevalence of adult systemic lupus erythematosus in a large US managed-care population," Lupus, vol. 22(1), pp. 99-105, January 2013.

[15] R.W. Jakes, S.C. Bae, W. Louthrenoo, C.C. Mok, S.V. Navarra, N. Kwon, "Systematic review of the epidemiology of systemic lupus erythematosus in the Asia-Pacific region:prevalence, incidence, clinical features, and mortality," Arthritis Care Res. (Hoboken), vol. 64(2), pp. 159-168, February 2012.
[16] S.V. Lourenço, F.R. de Carvalho, P. Boggio, M.N. Sotto, M.A Vilela, E.A. Rivitti, M.M. Nico, "Lupus erythematosus: clinical and histopathological study of oral manifestations and immunohistochemical profile of the inflammatory infiltrate," J. Cutan. Pathol., vol. 34(7), pp. 558-564, July 2007.

[17] R. Mina, H.I. Brunner, "Update on differences between childhood-onset and adult-onset systemic lupus erythematosus," Arthritis Res. Ther., vol. 15(4), pp. 218, August 2013.

[18] J.P.M. Filho, R.L. Peixoto, L.G. Martins, et al., "Lupus erythematosus: considerations about clinical, cutaneous and therapeutic aspects," Anais Brasileiros de Dermatologia, vol. 89(1), pp. 118-125, 2014.

[19] M. Petri, A.M. Orbai, G.S. Alarcón, et al., "Derivation and validation of the systemic lupus international collaborating clinics classification criteria for systemic lupus erythematosus," Arthritis Rheum., vol. 64(8), pp. 2677-2686, Agust 2012.

[20] S. Patil, S. Maheshwari, "Prevalence of lip lesions in an Indian population,” J. Clin. Exp. Dent., vol. 6(4), pp. e374-378, October 2014.

[21] M.M. Nico, M.A. Vilela, E.A. Rivitti, S.V. Lourenço, "Oral lesions in lupus erythematosus: correlation with cutaneous lesions," Eur. J. Dermatol., vol. 18(4), pp.376-381, July 2008.

[22] C.H. Orteu, J.A. Buchanan, I. Hutchison, I.M. Leigh, R.H. Bull, Systemic lupus erythematosus presenting with oral mucosal lesions: easily missed?" Br. J. Dermatol., vol. 144(6), pp. 1219 1223, June 2001

[23] M.M. Nico, S.B. Bologna, S.V. Lourenço, "The lip in lupus erythematosus," Clin. Exp. Dermatol., vol. 39(5), pp. 563-569, July 2014.

[24] D. Mardiani. (2017, September 26) Penyakit Lupus di Indonesia meningkat. Available: http://gayahidup.republika.co.id/berita/ gayahidup/infosehat/13/05/23/mn7mhx. 